\title{
Studies on the influence of accounting standard reform to construction enterprise accounting
}

\author{
Ying Wei \\ Loudi Vocational and Technical College, Loudi Hunan, 417000, China
}

Keywords: Accounting standard, Construction enterprise, Accounting, Influence.

\begin{abstract}
Strengthening accounting can perfect and consummate Chinese socialist market economy system, effectively improve the effectiveness of market economy, and can also further improve enterprise financial staff's professional quality, and improve capital utility efficiency. To conform to International Accounting Standards, financial department has gradually reformed enterprise accounting standard. This article has mainly started from the characteristics of construction enterprise accounting, and specifically analyzed and elaborated influence of accounting standard reform to construction enterprise accounting, and purposefully proposed relevant reinforcement strategies.
\end{abstract}

\section{Introduction}

To promote China's enterprise accounting standard system construction, in 2014, Ministry of Finance has conducted a large scale regulation on enterprise accounting standard and the revision is another important reform of the new account standard issued in 2006. Accounting standard reform has influenced our construction enterprise accounting to a certain degree. Accounting refers to make systematic records on the process and results of enterprises, institutions' budget or production operation activities with currency as the unit of measurement, and make regular compilation so as to establish relevant cost index and financial statement for providing accurate and reliable data for decision-making. New accounting standard system has positive promoting effect on the confirmation and measurement to standardize the confirmation and measurement of economic matters and improve the quality of account information.

\section{Analysis on specific features of construction enterprise account}

\section{Singleton of construction enterprise production}

Singleton of construction enterprise production is reflected in different projects and different construction key points. Thus, during the specific operation process, construction enterprise shall strictly confirm each project product according the particularity of project engineering, specific function and product requirements. During the process, geological conditions and climate conditions will influence the construction environment to different degrees. Even the same construction drawing, work progress and construction effect will not be the same.

\section{Accounting subject setting is concentrated in engineering construction industry}

In most cases, construction enterprises obtain profits through contracting project engineering by providing relevant mechanical hoisting construction, building installation construction and relevant engineering activities for profit increase. In this process, construction enterprise accounting will focus on cost expenses and other subjects which are usually divided into two cases: direct and indirect, but in a simple category of income subjects and simple contents. Direct expenses can be divided into labor costs, raw material costs, machinery costs and other costs. Based on different construction features, these costs can be categorized into subjects: revolving materials, mechanic operation, amortization of temporary installation, engineering construction, and engineering settlement. Unlike other accounting subjects, accounting subject setting is concentrated in construction enterprises. 


\section{Accounting staffs' working environment is special}

Accounting staffs in construction enterprise should be qualified with high-level accounting skills and relevant architecture knowledge. In addition, compared to other accounting staff's working environment in other industries, accounting staffs in construction enterprise should work in office but also need to go into the project site for field accounting.

\section{Cost carry-over of constructional engineering is special}

According to "ASBE-Construction Contract" and "Methods on Construction Enterprise Accounting", construction enterprise cost carry-over should separately handle the confirmed income with the project settlement amount, which is different with traditional method dealing with both together. Contract gross profits and costs occurred during project construction engineering can be completely reflected in account item of "project construction".

\section{Influence of new accounting criterion on construction enterprise accounting}

\section{Posive influence of new accounting criterion on construction enterprise accounting}

\section{Siplificaion of project settlement procedures}

According to old accounting principle, construction enterprises combine the revenue recognition with project funds for settlement, i.e. to confirm the income and costs of project settlement during the specific settlement process. Construction enterprise accounting is reflected in cost expenditure. Compared with the old system, new criterion connects with the international standard, thus improves the standardization and professionals in accounting. Specifically, it is reflected in following aspects: firstly, carry out independent settlement business, and precisely control the fund amount occurred in construction process and the project funds of settlement; secondly, deal with the income separately, thus, construction account can reflect the project cost occurred in project construction process objectively. In new accounting principles, project settlement is an important aspect of project engineering construction. After project completion, settled funds in project settlement occurred in the confirmation can be found with the relation between cost and gross profits during

Incorporate non-currency benefit into worker's salary

Old accounting criterion has not formed a completed and systematic worker's salary system which has a scattered, inaccurate and imperfect cost accounting on manpower. But new accounting criterion sets the essence of salary as the standard, and defines worker's salaries in a comprehensive and dimensional way. Meanwhile, in old accounting principle, worker's salary account has not elaborated the non-currency benefits. But new accounting principle has proposed following aspects to incorporate non-currency benefits provided by construction enterprises into worker's salary, and clarified relevant accounting handling methods: firstly, provide commodities or service subsidized by construction enterprise for workers; secondly, commodities produced by construction enterprises or purchased products are given to workers as welfare; thirdly, construction enterprises freely provide houses and other properties for workers and endow them the right to use or lease. Incorporating non-currency benefit into worker's salary is actually the restriction of enterprise "off-balance sheet benefits", as well as an expansion of worker's salary issuing method and scope, which has clarified the salary relation between enterprise and worker and reduced the possibility that construction enterprise control artificial costs.

Clarify the standard of construction contract separation and establishment

New and old accounting standards are basically consistent in the regulations of construction contract separation and establishment. But new accounting standard has added a standard of contract separation and establishment of "appended properties". Specifically, as long as any following term can be satisfied, it can be regarded as a spate contract: firstly, during the process of researching the construction cost of appended capital without considering the original contract amount; secondly, there exist some differences of design, construction and function between the appended capitals and capitals in original contract. Then new accounting standard will set more reasonable and scientific standards on the evaluation of construction contract construction contract separation and establishment so as to lay foundation to guarantee capital completeness and help construction enterprises have clearer standard on construction cost and project profits. 


\section{Negative influence of new accounting criterion on construction enterprise accounting}

Old accounting system has made clear opposite vertex in the calculating method of inventory, and ca use first-in first-out method, last-in first-out method, moving average method, individual pricing and method of weighted mean. After the issuing of new accounting standard, it has effectively changed the inventory pricing and canceled the last-in first-out method. Compared with last-in first-out method, first-in first-out method requires a comprehensive consideration of relevant cos price of raw materials lastly purchased during the process of cost accounting. Thus, for those large-scale enterprise with long inventory time and quantity, after using new accounting standard, their profits will fluctuate greatly. Introducing a large amount of fair value metering method into new accounting standard so as cause serious influence on construction enterprise asset revaluation, thus it has reduced the authenticity and objectivity of accounting information.

As a new property of accounting measurement, fair value metering refers to the limit involved during transaction parties' settlement of obligation or exchange of assets on voluntary basis in equal trade. Application of fair value measurement must be with relevant precondition, i.e. enterprise accounting working staffs must obtain high authentic fair values, but with regional price or imperfect market economy system will have some effect on fair value measurement. Once failure of obtaining fair values, advanced value evaluation technologies are required to take accurate evaluation. But in actual operation process, different evaluation technologies can work out different accounting information so as to greatly reduce the objectivity and intelligibility. If fair value of profit and loss is regarded as the current profit and loss, enterprise profits are very easy to be controlled by others so as to have serious influence on the reliability of accounting information. Specifically, it can be reflected in following aspects: Firstly, in a long term, it seems no big influence but will have certain influence on short-term enterprise profit and loss; secondly, in practical operation, construction contract is mainly conformed according to the completion to income expense ratio so as to cause the average profit in the process of whole project construction. In addition to the long period of construction, it is hard to objectively reflect the profit and loss in a certain period in the construction; thirdly, in actual construction process, gross profits of each construction period are different greatly, without a strict corresponding relation between completion degree and cost investment. It means that it is not scientific for make cost accounting based on completion ratio, which cannot reflect the real profits in a certain period of the construction contract engineering, thus it has serious influence on the large-scale construction enterprises which own multi-project construction.

\section{Strategic analysis on strengthening construction enterprise accounting under new accounting standard}

\section{Establish the new concept of construction enterprise accounting}

Specifically, it is reflected in following aspects: firstly, establish and perfect of modern enterprise accounting system, and change old accounting concept for solidification of cost effectiveness, and use the method of backward cost to reduce enterprise operation cost; secondly, establish the concept of risk and income coexistence. In other words, company's risk shall be in proportional to income. In the case with certain incomes, companies should take reasonable measures and try to reduce risks; thirdly, make reasonable allocation of resources, construction enterprise relevant project engineering must coordinate the structure and power ratio and increase the effective utility of resources, and improve enterprise economic effectiveness and social effectiveness.

\section{Constanty perfect and consummate construction enterprise interior supervision management system}

As construction enterprise financial accounting is special, enterprise interior supervision management is more important. It is mainly reflected in following three aspects: firstly, environmental control, i.e. construction enterprise relevant management staffs' attitude and behaviors on interior control and understanding of the significance; secondly, accounting system is the key procedure for construction enterprise to strengthen interior control, i.e. construction enterprises an use financial system for confirming, recording, measuring and reporting relevant information of economic business in building trade. By applying this system, relevant economic business will intensively feedback to accounting statement; thirdly, process control. Construction 
enterprises use relevant control program based on their own features including legality control, authorization control, planning control, and decentralization control, etc.

\section{Pay great attention to the establishment of construction enterprise culture}

As an important intangible asset of construction enterprise, corporate culture construction requires for the support and participation of mass staffs. In recent years, many construction enterprises have incorporated enterprise culture construction into enterprise routine management, to effectively improve enterprise interior management level and effectiveness and have positive effect on enterprise accounting management.

\section{Constantly perfect and consummate the financial accounting information construction in construction enterprises}

Construction enterprises should effectively improve information quality and sharing so as to achieve the dynamic management and concentrated management of accounting so that its financial accounting can step from headquarter to the whole enterprise and effectively improve the rationality and scientificity of financial resource allocation.

\section{Innovate thinking and strengthen the cultivation of professional judgment ability}

New accounting standard pays great attention to professional judgment ability cultivation, in the hope of effectively solving major issues and difficulties in accounting field through scientific ways so that accounting information issuer and user can positively interact and improve construction enterprise accounting level. This requires enterprise accounting working staffs can change traditional concepts, innovate thinking and effectively improve their own professional judgment ability, and timely solve different issues occurred in the working process.

\section{Essentially improve the accounting working staffs' professional ability and comprehensive quality}

Specifically, it is mainly reflected in following aspects: firstly, strengthen professional ethics education, establish models, and enhance the punishment on acts contrary to professional ethics; secondly, provide regular business training for accounting working staffs and effectively improve their professional ability and comprehensive quality; thirdly, further increase the transparency of accounting work, encourage employees to participate into enterprise management, which can effectively improve the economic risk control ability and prevent corruption, and to lay solid foundation for enterprise healthy and sustainable development.

\section{Conclusion}

To sum up, enterprises should adapt to different policy changes and meet the demand of reform, enhance accounting operation and theories, and deeply research the influence of account standard reform on accounting practice. As the pillar industry of national economic development, construction enterprise participation in international market competition is an inexorable trend of industry development. Thus the implementation of new accounting criterion has important realistic significance for the comprehensive development of construction enterprise. Construction enterprises should fully obtain the new accounting criterion, strengthen and standardize financial accounting, grasp chances and effectively improve their own market competitiveness and comprehensive power.

\section{Reference}

[1] Wang Wei. Analysis on strengthening construction enterprise accounting under new accounting criterion, Modern Business Trade Industry.2013(12):89-90.

[2] Jiang Feng. Discussion on construction enterprise accounting under new accounting criterion, Money China(Academic Edition).2013(09):112-113. 
[3] Zhang Xianzhi, Fu Rong, Jia Xingfei, Yan Chao. Multi-angle analysis of the influence of accounting standard reform on enterprise concept and behavior, Accounting Research.2014 (06):212-213.

[4] Zhang Wenquan. Brief analysis of the influence of new accounting criterion change on enterprise accounting,Guide to Business. 2012(02):56-57. 